\title{
Part IV. Bellagio Declaration
}

\section{Nutrition and health transition in the developing world: the time to act}

We from Africa, the Middle East, Asia, Europe and the Americas, met asparticipants in the meeting on the Nutrition Transition and its Implications for Health in the Developing World, held at the Rockefeller Centre at Bellagio, Lake Como, Italy, under the auspices of the International Union of Nutritional Sciences, declare as follows.

The control and prevention of undernutrition is unfinished work in many countries. At the same time nutrition-related chronic diseases are now the main causes of disability and death, not only globally but also in most developing countries.

Evidence presented at our meeting supports and reinforces evidence already accepted by the World Health Organization and many national governments, and proves that the patterns of disease throughout the developing world are changing rapidly.

Changes in food systems and patterns of work and leisure, and therefore in diets and physical activity, are causing overweight, obesity, diabetes, high blood pressure, cardiovascular disease including stroke, and increasingly cancer, even in the poorest countries. Malnutrition early in life, followed by inappropriate diets and physical inactivity in childhood and adult life, increases vulnerability to chronic diseases.

Evidence from many developing countries discussed at the meeting shows that nutrition-related chronic diseases prematurely disable and kill a large proportion of economically productive people, a preventable loss of precious human capital. This includes countries where HIV/AIDS is a dominant problem. Four out of five deaths from nutrition-related chronic diseases occur in middleand low-income countries. The burden of cardiovascular disease alone is now far greater in India, and also in China, than in all economically developed countries in the world added together. Low-income communities are especially vulnerable to nutrition-related chronic diseases, which are not only diseases of affluence.

Obesity, itself a disease, also predicts more serious diseases. Current rates of overweight and obesity - most of all in children, young adults and women - project rapidly increasing disability and premature death from nutrition-related chronic diseases for most developing countries. Phenomenal social and economic changes, on a scale and at a speed unprecedented in history, have resulted in an epidemic of nutrition-related chronic diseases that must be contained.
Prevention is the only feasible approach to nutritionrelated chronic diseases. The cost of their treatment and management imposes an intolerable economic burden on developing countries. There is an urgent need for governments, in partnership with all relevant constituencies, to integrate strategies to promote healthful diets and regular physical activity throughout life into all relevant policies and programmes, including those designed to combat undernutrition.

Chronic diseases are preventable. Successful programmes in a few developed countries have already demonstrated this. Their chief causes are smoking, inappropriate diet and nutrition, and physical inactivity. Exposure to these factors is largely determined by political, economic and commercial policies and practices, which reflect decisions made at national and transnational levels.

Effective programmes and policies will include not only health promotion and education, but also community empowerment and action to overcome the environmental, social and economic constraints to improvement in dietary quality and reduction of sedentarianism. Finland and Norway have succeeded in reversing, over a short time span, extremely high levels of nutrition-related chronic diseases through comprehensive food policy and community involvement.

Several examples of innovative and promising approaches in developing countries emerged from the meeting. These include: promotion of daily physical activity through massive community participation as in Agita São Paulo in Brazil; protection of healthful aspects of the traditional low-fat/high-vegetable diet as in South Korea with strong support from home economics and dietetic professionals and infrastructure; selective price policies promoting consumption of soy products in China; and development of food-based dietary guidelines in several countries based on local disease patterns and available foods. School-based programmes to promote healthy diets and physical activity are an especially valuable opportunity for action early on, which should protect health over the life span. Examples are the national school food programme in Brazil that provides fresh, unprocessed food to school children and the new national physical activity programme in Thailand.

Immediate action to control and prevent nutritionrelated chronic diseases is not only a public health imperative but also a political, economic, social necessity. 
Successful programmes will be multidisciplinary and intersectoral, and will include government, industry, the health professions, the media and civil society, as well as international agencies, as partners.

We, present at this meeting, pledge ourselves to be part of this process.

Agreed at the Rockefeller Centre at Bellagio, Lake Como, Italy

Thursday 24 August 2001

At the meeting in Bellagio papers were presented from Egypt, Morocco, Tanzania and South Africa; Cuba, Mexico, Brazil and Chile; Iran; and India, China, Thailand, Malaysia and South Korea. Material showing information and trends from Africa, Latin America, the Middle East and Asia was also reviewed. Senior officials from the World Health Organization in Geneva, and from the Food and Agriculture Organization of the United Nations in Rome, were also present at the meeting as observers.

The group met at Bellagio responsible for this Declaration proposes to continue to work together, initially as members of the IUNS Task Force on the Nutrition Transition and its Implications for Health in the Economically Developing World, in consultation with United Nations, international and bilateral agencies, national governments and other constituencies.

Barry Popkin, Convenor

University of North Carolina at Chapel Hill, USA

Cecilia Albala

Instituto de Nutricion y Tecnologia de los Alimentos (INTA), Chile

Sabah Benjelloun

Institut Agronomique et Vétérinaire Hassan II, Morocco

Lesley Bourne

Medical Research Council, South Africa

Geoffrey Cannon, Rapporteur

World Health Policy Forum, Switzerland

Denise Coitinho

Ministry of Health, Brazil

Colleen Doak

University of North Carolina at Chapel Hill, USA

Osman Mahmoud Galal

High Institute of Public Health, Alexandria University, Egypt
Hossein Ghassemi

Formerly Director, National Study on Food and Nutrition Security in Iran, Iran

Gail Harrison

UCLA School of Public Health, USA

Vongsvat Kosulwat

Institute of Nutrition, Mahidol University, Thailand

Min-June Lee

The Graduate School of Human Environmental Science, South Korea

Tumsifu Maletnlema

Child Growth Promotion Union, Tanzania

Victor Matsudo

CELAFISCS, Brazil

Carlos Monteiro

São Paulo University, Brazil

Mohd Ismail Noor

Universiti Kebangsaan Malaysia, Malaysia

K Srinath Reddy

All India Institute of Medical Sciences, India

Juan Rivera

Instituto Nacional de Salud Publica (INSP), Mexico

Arturo Rodriguez-Ojea

Instituto Superior de Ciencias Medicas de La Habana, Facultad de Ciencias Medicas, Cuba

Ricardo Uauy

Instituto de Nutricion y Tecnologia de los Alimentos (INTA), Chile

Hester H Vorster

Potchefstroom University for CHE, South Africa

Zhai Fengying

Chinese Academy of Preventive Medicine, China

Observed and acknowledged by:

Pekka Puska

World Health Organization, Geneva

Prakash Shetty

Food and Agriculture Organization of the United Nations, Rome 